\title{
On the meaning of service
}

A s a nephrologist, despite all our machines, protocols and interventions, I have often been most humbled by the courage and instincts of our patients and the undeniable wisdom of the body. After 20 years of practice, I know I still have much more to learn, but am also less starry eyed about the revolutionary benefit of many sophisticated medications and procedures. I am increasingly convinced that one's interaction with the patient - gaining and deserving their trust — is at least as important as our technical skills. My role is not only to inform, to suggest, to prescribe, but also to be a companion and try to meet a patient's needs along the winding road of chronic illness. This role of service is where I have found my resonance between science and humanity.

I vividly remember a third-year pharmacology lecture where an elderly, grumpy professor silently put a handscribbled sheet on the overhead projector: "To cure sometimes, to relieve often, to comfort always." ${ }^{1}$ This statement suddenly crystallized for me the essence of medical practice. As a student, however, I was not totally convinced about this professor, who was rather impatient and very demanding, and I wondered how empathic he could be. Then, several years later, my mother was undergoing peritoneal dialysis and kept coming home with great appreciation for her doctor: the same grumpy professor, living up to his famous words. I was deeply impressed!

As a resident I was somewhat intimidated by dialysis patients, these were "professional" patients, they knew the hospitals inside out and knew how to sort the men from the boys. This feeling shifted in me late one Friday night. I was the fellow on call, working with a nurse called Joy, a tiny lady with lots of makeup and lots of energy, who truly lived up to her name. We had a patient whose fistula was not working for the umpteenth time, she had been through an unpleasant procedure and was totally

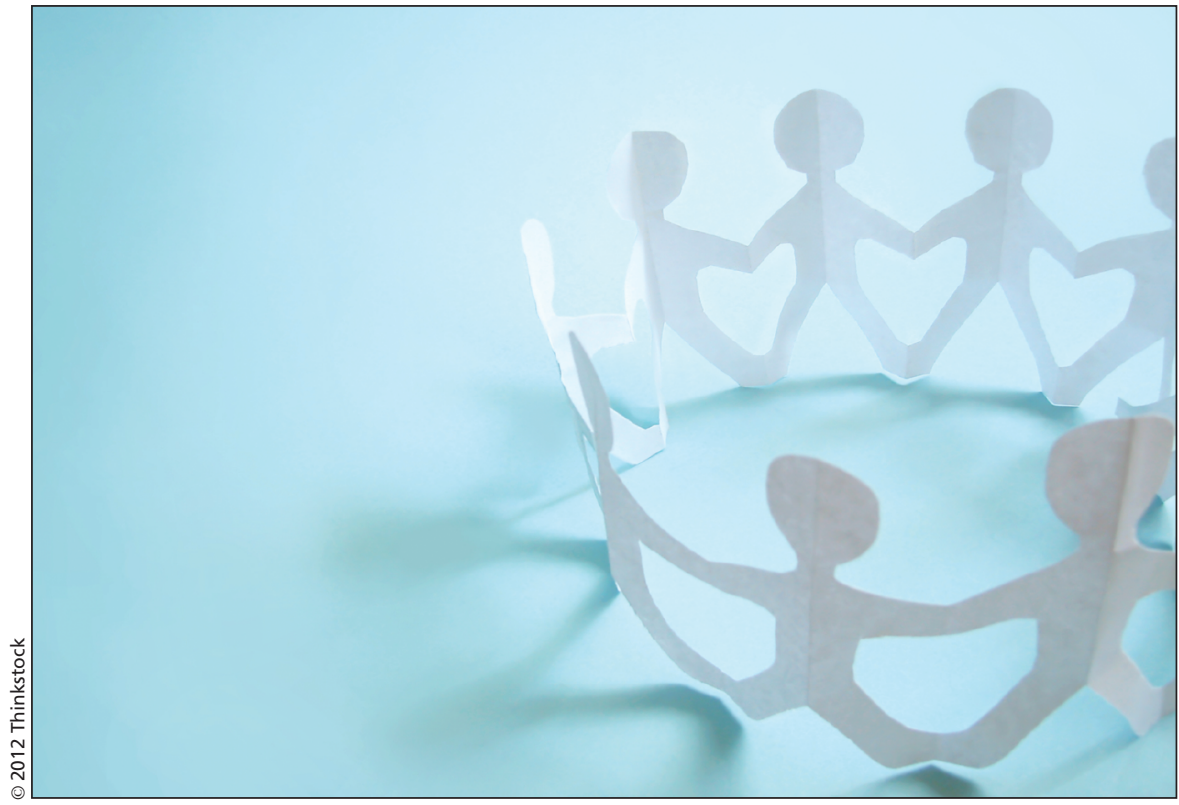

exhausted. She was blind, had no legs, could barely speak English, and was not happy to be there. Joy called out her name as she was wheeled into the dialysis unit and gave her a big hug. I was moved, to see the patient's unseeing eyes light up. Joy was not put off by the patient's less than clean clothes and awkward appearance ... she loved the patient. Joy knows more about dialysis than I will ever know, but more than facts, she taught me to love and admire these patients.

The families of patients on dialysis are also unsung heroes. We recently looked after a young man who was extremely debilitated, he lived in a remote area but was too weak to get home. His doting parents, immigrants from the UK, told me their story. They had few prospects in England and had come to Canada many years ago to build their lives. They adopted this boy "with a heart of gold," who later developed kidney failure. His dialysis became a team effort. Dad and Mom took turns during the day to do his peritoneal exchanges, mastering the technique and keeping him alive and healthy. He finally received a deceased donor transplant, but now, 23 years later, this kidney had failed and he was on hemodialysis which presented a big problem as there was no dialysis in their town. The father, by now older, was willing to drive $140 \mathrm{~km}$ on treacherous roads for dialysis three times a week, to allow his son to get home to his threeyear-old son. What was most humbling to me was that these two gentle parents kept repeating how medicine had been so great to their family, how great we doctors were ... and all I could think and say was, "You know much more than we do, you have done much more than any of us have to keep your son alive." They knew what their son needed to get better: not only drainage catheters and antibiotics, but more importantly, hope. The magnitude of love in these parents' hearts made us more determined to find a potential solution, suddenly the patient started hurtling around with physio and became strong enough to be moved. We have since learned that this family has surmounted another challenge and mastered home hemodialysis.

Recently, a seasoned dialysis patient was brought down from a remote area where she had been failing to thrive. 
She had diabetes since age 11, and had suffered almost every ravage of that disease. The nurses and housestaff were frustrated with her and she was labelled "difficult." She insisted on checking her own blood sugars but refused to do this at night, and her sugar control was very erratic. After several weeks we called for help from a senior endocrinologist, who asked the simple question "why" the patient had to check her sugars herself. Her reason turned out to be very logical and appropriate, based on strict instructions from her peritoneal dialysis nurses. It took an experienced and open clinician, giving the patient the benefit of the doubt, to get to the truth.

This experience taught us two valuable lessons: first, take time to understand why a patient is doing something that does not seem to make sense, and second, avoid labelling patients. Labelling happens a lot in patients with chronic illness, one sees phrases like "noncompliance" on patients' problem lists. I believe our function as clinicians is to present options to the patient. They know their lives and their bodies. We must inform them so they understand why we suggest what we do, but ultimately they are usually quite competent to decide on their own behaviour, and we have no right to be patronizing or judgmental.

In Africa there is a wonderful saying "umuntu ngumuntu ngabantu," a human is a human because of other humans. In no other profession is this more true than in ours. I have trained and worked in many places, from clinics under a tree in Africa, to the biggest ivory towers of medicine. I have realized that first-world patients, from the homeless drug addict to the world- famous concert pianist, have the same vulnerability as the poorest in developing countries. One does not have to travel far to serve.

A wonderful and inspiring physician, Dr. Rachel Remen sums up the meaning of service very distinctly: " True service is not a relationship between an expert and a problem ... it is a relationship between people who bring the full resource of their combined humanity to the table and share them generously. Service goes beyond expertise. Service is another way of life ... service is a relationship between equals ... In helping, we may find a sense of satisfaction $\ldots$ in serving we have an experience of gratitude."

\section{Valerie Luyckx MBBCH \\ Nephrologist \\ Edmonton, Alta.}

This article is adapted from the keynote address the author presented to the Student Clinician Ceremony and Humanism and the GHSS Excellence in Teaching Awards, University of Alberta, August 2010.

Consents have been signed by the patients and staff depicted in this essay.

\section{References}

1. Russel IJ. Consoler toujours - to comfort always. J Musculoskeletal Pain 2000;8:1-5

2. Ramen RN. My grandfather's blessings. Stories of strength, refuge and belonging. New York (NY): Riverhead Books; 2000.

CMAJ 2012. DOI:10.1503/cmaj.110766

\section{More Humanities online}

\section{Essay}

Skill, drive and luck: the discovery and development of heparin. One of the oldest drugs still in clinical use will soon turn 100. Its discovery begins with a meeting between a poor, but determined, medical student and a celebrated researcher and

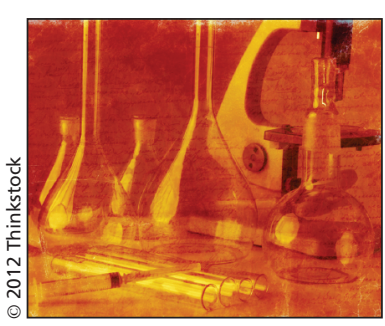
author. Much of its translation into clinical practice occurred in Toronto under the oversight of Charles Best - yes, of insulin fame. - Richard Norman BSC MASc, Toronto, Ont.

\section{Encounters}

Grey. "Everything seemed wrong from the get-go. Nobody said anything." A medical student reflecting on the death of a patient finds "... I don't remember his face or his name. I feel nothing, just a vast emptiness amidst a field of grey." - Alim Nagji BHSc, Edmonton, Alta.

\section{Poetry}

The explosion at a Glock Plant in Georgia, by Ron Charach MD, Toronto, Ont.; I went to the cenotaph today, by James Stephenson, St. John, NB; Quartet of remembrance, by lan Scott MD MSc, Vancouver, BC; The featherweight fighter, by Ryan Childers MD, Baltimore, Md.; Table of contents, by Adam Possner MD, Washington, DC; Death's brother, by Gayle Greene PhD, Claremont, Calif.; A goodbye, by David M. Kaplan MD MSc, Toronto, Ont.; The lady vanishes, by Arash Emamzadeah BA, Burnaby, BC

\section{Books}

My imaginary illness: A Journey into Uncertainty and Prejudice in Medical Diagnosis, Chloë G.K. Atkins (Cornell University Press; 2010). At the age of 20, Chloë Atkins became ill. Twenty years later, after innumerable physicians and emergency visits, scores of tests and accusations of malingering, she was still ill. This is a cautionary tale about how we can so utterly fail those most in need. - Dennis Rosen MD, Boston, Mass.

Sorrow's Reward, Robert Allan Bear. (Kingsley Publishing; 2011). In the crucible of the dialysis unit, patients are all changed - but most for worse rather than for better. This novel adapts two stylistically different stories to examine the microcosm of the dialysis unit and the various members of that "community." - Vincent Hanlon MD, Lethbridge, Alta.

CMAJ 2012. DOI:10.1503/cmaj.120542 